


\title{
BEIHEFTE
}

\author{
ZUR \\ ZEITSCHRIFT \\ FUR

\section{ROMANISCHE PHILOLOGIE}

BEGRUNDET VON Prof. Dr. GUSTAV GROBER †

\author{
FORTGEFUHRT UND HERAUSGEGEBEN \\ voN \\ DR. WALTHER v. WARTBURG
}

PROFESSOR AN DER UNIVERSITÄT LEIPZIG

LXXXVIII. HEFT

WILHELM KELLERMAN N

AUFBAUSTIL UND WELTBILD CHRESTIENS VON TROYES IM PERCEVALROMAN

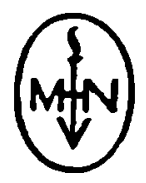

MAX NIEMEYER VERLAG / HALLE/SAALE I936 


\section{AUFBAUSTIL UND WELTBILD CHRESTIENS VON TROYES IM PERCEVALROMAN}

VON

WILHELM KELLERMANN

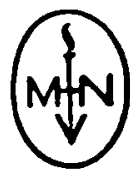

MAX NIEMEYER VERLAG / HALLE/SAALE I936 
Alle Rechte,

auch das der Übersetzung in fremde Sprachen, vorbehalten

Copyright by Max Niemeyer Verlag, Halle (Saale), $193^{6}$

Printed in Germany 
MEINER FRAU 
